\title{
Mar de Histórias e o conceito de Bildung
}

\author{
Adauto Villela*
}

RESUMO: Mar de Histórias: Antologia do Conto Mundial é uma obra em dez volumes que reúne contos das mais diferentes origens nacionais e linguísticas, abrangendo um período que vai da antiguidade ao entreguerras. Essa grande empreitada tradutório-literária foi levada a cabo por Paulo Rónai e Aurélio Buarque de Holanda. O objetivo deste artigo é interrelacionar à obra o conceito de Bildung, tal como estudado por Antoine Berman (2002), sob três aspectos: enquanto princípio orientador da organização do projeto; enquanto base para a descrição panorâmica da antologia; e enquanto ferramenta para a Bildung de novos escritores.

Palavras-chave: literatura mundial; tradução; antologia; Bildung, Paulo Rónai; polissistemas.

\section{Introdução: os organizadores e sua obra ${ }^{1}$}

A origem de Mar de Histórias pode ser fixada no ano de 1942, quando a Segunda Guerra Mundial estava ainda em andamento. Paulo Rónai (Budapeste, 1907 - Nova Friburgo, 1992), de família judaica, viera para o Brasil em 1941 como exilado, pois seu país Natal, a Hungria, após estreitar laços com governos nacionalistas, principalmente a Itália de Benito Mussolini, passara a perseguir e aprisionar judeus. O próprio Rónai chegou a ficar seis meses em um "campo de trabalho", tendo aproveitado um indulto de Natal para, graças a relações de amizade mantidas com diplomatas brasileiros, sair da Europa e vir para o Brasil. ${ }^{2}$

Pouco tempo depois de desembarcar no Rio de Janeiro, em 3 de março de 1941, Rónai encontraria Aurélio Buarque de Holanda Ferreira (Passo de Camaragibe, 1910 - Rio de Janeiro, 1989) na redação da Revista do Brasil, onde este último trabalhava como redator-chefe. De um contato profissional, pois Rónai havia ido até a Revista para tentar publicar um artigo seu redigido em francês, surgiu uma amizade que duraria toda a vida, e vários projetos que levaram a cabo juntos, sendo o mais vultoso a antologia Mar de Histórias. Conforme explicou Rónai no número 2 da revista Tradução \& Comunicação, especialmente dedicado a relatos sobre a tradução de grandes obras literárias:

\begin{abstract}
A primeira ideia da obra ocorreu-nos, a Aurélio e a mim, em 1942, e sua história está ligada inseparavelmente à de uma longa e constante amizade. [...] Eu tinha chegado havia pouco da Europa convulsionada, e a minha boa sorte me pôs logo em contato com ele [...]. Não levamos muito tempo a descobrir que tínhamos em comum a paixão da literatura. Nossas visitas às livrarias convenceram-nos de que faltava uma boa coletânea de contos estrangeiros (RÓNAI, 1982, p. 2-3).
\end{abstract}

Como se vê, num primeiro momento foi a identificação de uma demanda, a falta de uma coletânea de contos estrangeiros, o que deflagrou a ideia de uma parceria para a tradução e publicação de contos. Porém, Rónai e Aurélio pensaram em uma antologia abrangente, que englobaria várias literaturas e idiomas de partida, uma vez que coletâneas do tipo "Os melhores contos ingleses" já existiam, mas eles vislumbraram algo diferente. Complementando seu relato, Rónai nos informa:

Depois de tateamentos iniciais, a ordem cronológica foi aceita como princípio ordenador da antologia. Quer dizer que não haveria, como na maioria das obras desse gênero, uma seção reservada ao conto francês, outra ao inglês, outra ao espanhol e assim por diante. O mesmo volume conteria obras escritas em diversos países durante determinado período. O público assim teria uma ampla 
perspectiva do Romantismo, do Naturalismo etc. e poderia melhor perceber os seus traços distintivos (RÓNAI, 1982, p. 7).

Da concepção à publicação do primeiro volume de Mar de Histórias passaram-se cerca de três anos. A primeira edição desse volume saiu pela Editora José Olympio no ano em que terminou a Segunda Guerra Mundial, 1945, sendo esse o único volume lançado durante o chamado "período áureo" da tradução no Brasil (cf. PAES, 1990, p. 10). Entre o surgimento da ideia do projeto até a publicação do volume inicial, Rónai e Aurélio empenharam-se na seleção, tradução e organização do volume, bem como na redação de notas introdutórias para apresentar cada autor e também a inclusão de abundantes e generosas notas de rodapé. Tais procedimentos seriam empregados também nos os outros nove volumes da antologia.

Os volumes 2, 3 e 4 vieram a público pela mesma editora, nos anos de 1951, 1958 e 1963 respectivamente. Percebemos, portanto, intervalos de seis anos entre o volume 1 e o volume 2 , de sete anos do 2 para o 3 , e de cinco anos deste para o volume 4 . Depois do lançamento do quarto volume, o projeto seria temporariamente interrompido. Até onde pudemos apurar, a interrupção das publicações pela Editora José Olympio antes do lançamento do volume 5 foi motivada por questões operacionais da própria editora (RÓNAI, 1982, p. 2). Até que aparecerem novos volumes, haveria a publicação de uma segunda edição, viabilizada agora por outra editora, a Nova Fronteira. A partir de 1978, os quatro volumes iniciais foram reeditados na seguinte ordem: o volume 1 - 1978; o volume 2 - 1979; volumes 3 e 4 - 1980 (RÓNAI, 1981, p. 169).

Nesse intervalo de 15 anos entre a primeira e a segunda edição, Rónai e Aurélio continuaram levando o projeto adiante. Primeiro, com uma nova série de antologias, parcialmente derivada de Mar de Histórias, lançadas pelas Edições de Ouro (futuramente rebatizada como Ediouro) a partir de 1966: Contos alemães, Contos franceses, Contos italianos, Contos ingleses, Contos norte-americanos, Contos russos. Segundo Rónai, essas "miniantologias" tanto reaproveitaram contos publicados nos quatro primeiros volumes de Mar de Histórias quanto ensejaram oportunidade de tradução de outros contos, igualmente selecionados por iniciativa dos organizadores, cujo trabalho era "compensado sob forma de direitos autorais pagos depois da venda de cada volume" (1982, p. 17). Rónai e Aurélio prepararam os demais volumes valendo-se igualmente de sua colaboração, entre julho de 1954 e dezembro de 1960, com jornal Diário de Notícias que, durante esse período, publicou contos escolhidos e traduzidos por eles na coluna "O conto da semana" (SPIRY, 2009, p. 190-202). Ainda segundo Rónai, "algumas revistas, especialmente Senhor e Humbolt, auxiliaram-nos também, oferecendo uma publicação anterior à inclusão em volume" (RÓNAI, 1982, p. 18).

Retomada a publicação dos demais volumes pela Nova Fronteira a partir de 1978, como mencionado acima, os demais volumes foram saindo paulatinamente, sendo que o décimo, último da série, seria então publicado em 1987. O último volume de Mar de Histórias, portanto, foi publicado 42 anos após o primeiro volume da primeira edição vir a público e 45 após surgimento do projeto.

Uma característica comum aos organizadores do Mar de Histórias é a clara vocação didática que tinham, fato que engrandece ainda mais o objetivo que procuraram alcançar com a obra, como veremos adiante. Paulo Rónai exerceu o magistério, paralelamente a outras atividades editoriais e literárias, desde o início de sua carreira, ainda na Hungria. No Brasil, foi professor de francês no Colégio Pedro II, no Rio de Janeiro, lançou métodos didáticos de latim (Curso Básico de Latim: Gradus Primus e Curso Básico de Latim: Gradus Secundus), além de dicionários e outros livros de inclinação didática, como o Guia Prático da Tradução Francesa. De forma muito especial, por se tratar de um 
marco da valorização da profissão de tradutor e da reflexão sobre o fazer tradutório, é preciso lembrar que Escola de tradutores, cuja primeiro edição data de 1952, era direcionado sobretudo a tradutores iniciantes, enquanto seu outro livro dedicado ao tema, $A$ tradução vivida, resultou de uma série de palestras sobre tradução proferidas durante um curso. ${ }^{3}$ Podemos perceber essa mesma vocação didática nas introduções e notas de rodapé que acompanhavam as traduções que publicou, sempre buscando contextualizar a obra e o autor, bem como esclarecer termos e situações cuja distância no tempo ou na realidade sociocultural pudessem resultar em dificuldades de entendimento para o leitor. ${ }^{4}$ Em Mar de Histórias, contamos com 2.166 notas de rodapé, sendo que 951 delas foram incluídas no textos introdutórios de cada volume e nas apresentações dos autores, e outras 1.215 estão presentes nos próprios contos. Tais cuidados, além de esclarecer o leitor, como mencionado, prestam-se também a, de certa forma, educá-los sobre as respectivas questões abordadas, em grande maioria de cunho histórico, linguístico e cultural.

Quanto à vocação didática de Aurélio Buarque, um dos maiores dicionaristas brasileiros, mas igualmente autor e tradutor, encontramos no artigo "Aurélio, homem humano", assinado por Rónai e publicado na Revista USP à época da morte de Aurélio, o seguinte depoimento:

Fui, sem dúvida, o maior beneficiário da generosidade de Aurélio revisor: por mais de trinta anos, sem mesmo falar nos livros que assinamos juntos, ele teve a pachorra de rever todos os trabalhos do imigrante, ainda às voltas com os mistérios do português. Foi nesses anos que aprendi a admirar a sua probidade e a sua tolerância, o talento literário e a vocação didática. [...] Para ele, a revisão não se limitava a um exercício mecânico: timbrava em explicar-me o porquê de suas correções, para que não recaísse no mesmo erro. Essa insistência era uma das manifestações de sua vocação de professor, que fez com que o País inteiro o chamasse carinhosamente de "Mestre Aurélio". [...] A meus olhos era não somente a encarnação do espírito da língua portuguesa, como também o representante mais completo da cordialidade brasileira (RÓNAI, 1989, p. 32).

\section{A Bildung do conto como princípio organizador de Mar de Histórias}

Essa propensão didática dos organizadores tem relação direta com o conceito de Bildung, tal como apresentado por Antoine Berman em A prova do estrangeiro: cultura e tradução na Alemanha romântica (2002). Se inicialmente a ideia da obra surgiu como forma de preencher uma lacuna editorial percebida pelos organizadores, tendo eles tido o impulso de compartilhar com o leitor brasileiro o que sentiram ao ler "determinadas obrasprimas do gênero", posteriormente a antologia Mar de Histórias "acabou por transformarse na ousada pretensão de fazer dela uma espécie de introdução à literatura mundial" (RÓNAI, 1982, p. 4) e que "se destinava ao grande público, procurando conquistá-lo para a literatura de alto nível" (RÓNAI, 1982, p. 6). Isso, claramente, segue aquele viés didático, pois, ao trazer tantos contos selecionados a dedo durante anos, estavam também ensinando sobre o gênero conto e sobre a boa literatura mundial.

Podemos encontrar, no prefácio à $2^{\mathrm{a}}$ edição de Mar de Histórias - prefácio datado de 15 de março de 1976 e repetido nas demais edições -, a indicação feita pelos organizadores-tradutores de que os contos apresentados ali "são belos sem exceção e merecem leitura" (1999, p. 13). Além disso, lemos ainda no prefácio que cada conto possui uma originalidade própria, seja temática ou de construção do enredo, alguma particularidade estilística, tendo sido escolhido, também, devido "à importância que lhe cabe dentro da evolução do gênero e, nalguns casos, da própria civilização" (ibidem, ênfase acrescentada). Em seguida, o texto continua: 
Em vez de apenas alinhar à toa certa porção de contos, achamos melhor agrupálos de maneira que logo pudessem servir de marcos à história do conto na literatura universal. Por isso adotamos, na sucessão deles, a ordem cronológica mais precisa, e, por outro lado, procuramos escolhê-los dentro do maior número possível de literaturas, de tal modo que fossem característicos das civilizações de onde provêm. Assim, poderá o leitor, ao ler uma após outra as nossas histórias, acompanhar a progressiva depuração e cristalização do gênero, processo este que procuramos esclarecer, não só neste prefácio, mas ainda nas notas que precedem cada conto do livro (RÓNAI e FERREIRA, 1999a, p. 13-14).

Como podemos perceber, uma concepção que norteou a organização do projeto Mar de Histórias foi a de que o gênero conto foi se delineando ao longo do tempo, passando por uma evolução, um desenvolvimento de suas características peculiares. Ao se falar em conto como um gênero, geralmente é difícil de especificar o que é próprio dele e o que o distingue de outras narrativas curtas, como a fábula ou a novela. Em Mar de Histórias, percebemos a presença de obras classificáveis como outros gêneros além do conto, mas isso se dá precisamente porque os organizadores consideram que, junto com o desenvolvimento das línguas e literaturas nacionais, a forma ou gênero conto foi se desenvolvendo ao longo do tempo, incorporando e cristalizando elementos de outros gêneros até chegar a uma definição mais específica do que é próprio ao conto. Tais ideias de desenvolvimento e progresso está no cerne do conceito de Bildung, avaliado em detalhes por Antoine Berman (2002).

Segundo o autor, essa palavra é uma forma de raízes germânicas intercambiável pela palavra Kultur, esta de origem latina, mas a acepção de Bildung que mais interessa para nossa análise é a de "formação", sendo que a conotação pedagógica e educativa, também mencionada pelo autor, de "processo de formação" é particularmente pertinente para o gênero conto, tal como abrangido pelo projeto Mar de Histórias, havendo outras acepções ainda, como educação, instrução e organização (BERMAN, 2002, p. 79). Para entendermos como esse conceito pode ser aplicado enquanto princípio organizador da antologia Mar de Histórias, o trecho abaixo é de fundamental importância:

Pela Bildung, um indivíduo, um povo, uma nação, mas também uma língua, uma literatura, uma obra de arte em geral se formam e adquirem, assim, uma forma, uma Bild. A Bildung é sempre um movimento em direção a uma forma que é uma forma própria (BERMAN, 2002, p. 80, ênfase do autor).

O conceito de Bildung costuma ser correlacionado, de modo metafórico, a uma imagem ligada à vida orgânica, ao desenvolvimento pelo qual passam os seres do reino animal e vegetal, como, por exemplo, o fato de que uma semente vai se transformando até virar um botão, depois uma flor e, conforme o caso, um fruto; de forma semelhante, da gestação até a vida adulta, um ser humano passa por diversas fases de desenvolvimento. A Bildung parece caracterizar um processo necessário, como as metáforas orgânicas indicam. Esse processo constitui, igualmente, um desdobramento da liberdade (BERMAN, 2002, p. 80). Visto ser a Bildung é "um processo temporal e, portanto, histórico, ela se articula em períodos, em etapas, em momentos, em épocas" (BERMAN, 2002, p. 81).

Uma vez estabelecido o eixo cronológico como espinha dorsal da antologia, bastaria levar-se em consideração a data de publicação de cada conto. Porém, os organizadores tornaram mais complexa a tarefa ao se proporem a buscar pela forma própria do gênero conto, ao estabelecer como que uma "crítica genética", por assim dizer, não de um texto, um estilo ou tema em determinado autor ou época, mas do próprio gênero em todas as literaturas disponíveis à época no mundo ocidental, ou pelo menos em número 
significativo delas. Com isso, os organizadores, no trabalho crítico que é a seleção ${ }^{5}$, expandiram pouco a pouco suas buscas, tanto no eixo cronológico quanto do geográficoespacial:

\begin{abstract}
O hábito de ver os fenômenos literários dentro de uma perspectiva mais ampla levou-nos a investigar as origens do conto moderno, e essa pesquisa ia recuando cada vez mais os limites da coleção no tempo, enquanto os ampliava no espaço. Havia laços evidentes entre contistas dos nossos dias e os grandes cultores do gênero no século passado, um Maupassant, um Tchecov, um Machado de Assis; existiam ligações entre estes e os novelistas do humanismo, um Boccaccio ou um Bandello. Estes, por sua vez, eram herdeiros dos contistas orientais e, ao mesmo, tempo deviam algo aos autores anônimos da Legenda áurea. E assim íamos recuando cada vez mais, descobrindo os arquétipos do conto nas letras grecolatinas de um lado, em certos episódios da Bíblia e do Talmude do outro. Ficamos como que embriagados pela descoberta e resolvemos alterar as proporções do empreendimento (RÓNAI, 1982, p. 2).
\end{abstract}

Percebemos aí um trabalho minucioso, uma "garimpagem direcionada", partindo do presente, ou passado recente, e retrocedendo sobre uma linha onde se percebiam traços comuns, alguma possível influência ou intertextualidade, em relação a cada geração passada. Não se tratava mais de eleger os contos mais belos, nem simplesmente os mais conhecidos de cada autor, mas de identificar traços que permitissem vislumbrar uma linha evolutiva, uma Bildung do gênero conto. $\mathrm{O}$ intuito de compilar "uma espécie de introdução à literatura mundial" (RÓNAI, 1982, p. 4) e disponibilizar ao público uma "literatura de alto nível" (RÓNAI, 1982, p. 6) reflete a lógica das percepções filosóficas apresentadas por Berman sobre o conceito de Bildung que, inclusive, estaria na base da concepção goethiana de literatura mundial ou Weltliteratur (BERMAN, 2002, p. 79). Além disso, um outro aspecto da Bildung liga-se diretamente à tradução, prática fundamental e estruturadora de Mar de Histórias. Como destaca Suarez em seu estudo sobre o tema, "[a] natureza circular, cíclica e alternante de Bildung (isto é, ser, ao mesmo tempo, progressão e retorno) pode ser definida como Über-Setzung, um lançar-se-além-de-si, um movimento de tradução" (2005, p. 195).

Sem apresentar evidência de que conhecessem a teoria dos polissistema (EVENZOHAR, 1978), Rónai e Aurélio compilaram comprovações de que as literaturas não se limitam a espaços, culturas, idiomas e épocas isoladas, mas se interinfluenciam, se interconhecem, sempre mediadas, de alguma forma, pela tradução. Da mesma forma, o conceito de Bildung nunca foi citado por Rónai em seus escritos sobre tradução ou literatura, contudo, a construção do projeto Mar de Histórias parece refletir plenamente suas ideias fundamentais, justificando ter a antologia tomado as proporções que tomou.

\title{
Raio X da antologia: a Bildung de Mar de Histórias
}

Como mencionado na parte anterior, "[a] Bildung é sempre um movimento em direção a uma forma que é uma forma própria" (BERMAN, 2002, p. 80). Mar de histórias também chegou a sua forma própria na $2^{\mathrm{a}}$ edição, aquela publicada pela editora Nova Fronteira a partir de 1978. Enquanto essa foi a primeira edição completa, com 10 volumes, ajustes foram feitos em relação à $1^{a}$ edição, tanto que a $2^{a}$ traz o dístico "revista e ampliada", e podemos entender que isso vale para os 4 primeiros volumes, publicados nas décadas de 50 e 60 por outra editora, como também já citamos. Atualmente na sua $5^{\text {a }}$ edição, lançada pela Editora Nova Fronteira entre 2013 e 2014, Mar de Histórias é a mais completa antologia do conto mundial surgida no Brasil. ${ }^{6}$ Com base no já citado critério cronológico adotado pelos organizadores, temos os seguintes títulos para cada um dos 10 
volumes da antologia: Volume 1 - Das origens ao fim da Idade Média; Volume 2 - Do fim da Idade Média ao Romantismo; Volume 3 - O Romantismo; Volume 4 - Do Romantismo ao Realismo; Volume 5 - O Realismo; Volume 6 - Caminhos cruzados; Volume 7 - Fim de século; Volume 8 - No limiar do século; Volume 9 - Tempos de crise; Volume 10 Após-guerra.

Em números exatos, temos que os 10 volumes de Mar de Histórias, que na edição de 1999 somam 3.618 páginas, trazem 243 contos de 197 autores diferentes, visto que alguns autores participam com mais de um conto na antologia, dos quais 16 escreviam originalmente em português ( 7 portugueses e 9 brasileiros) e os demais 181 produziram suas obras em outros idiomas. Ao todo, os 197 autores representam 44 literaturas nacionais, com originais escritos em 32 idiomas diferentes. As literaturas representadas, adotando-se como referência os países natais dos autores, são, em ordem alfabética: alemã, árabe, austríaca, belga, brasileira, canadense, catalã, chilena, costarriquenha, cubana, dinamarquesa, egípcia, equatoriana, eslovena, espanhola, estadunidense, finlandesa, francesa, grega, hebraica, holandesa, húngara, iídiche, indiana, inglesa, italiana, japonesa, latina, letã, mexicana, neozelandesa, nicaraguense, norueguesa, persa, peruana, polonesa, portuguesa, romena, russa, sueca, suíça, tcheca, uruguaia e venezuelana.

Os 32 idiomas em que os contos foram originalmente escritos, também em ordem alfabética, são as seguintes: alemão, árabe, bengali, catalão, chinês, dinamarquês, egípcio, esloveno, espanhol, finlandês, flamengo, francês, grego, hebraico, holandês, húngaro, iídiche, inglês, italiano, japonês, latim, letão, norueguês, persa, polonês, português, romeno, russo, sânscrito, sueco, tcheco e turco.

Abaixo temos uma representação gráfica que indica a quantidade de contos para cada um dos idiomas em que foram originalmente escritos:

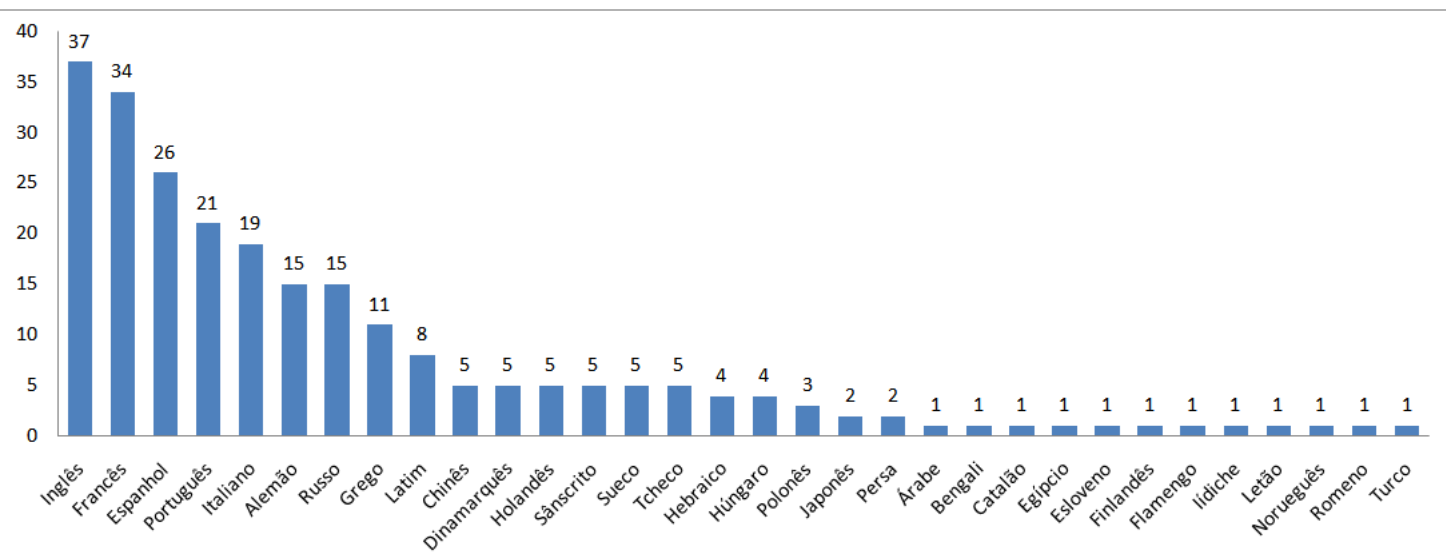

Figura 1: Número de contos para cada um dos 32 idiomas em que foram escritos os contos presentes em Mar de Histórias.

É notável, e compreensível, a preponderância do inglês como língua de partida. Embora tenhamos um número maior de literaturas de língua espanhola (chilena, costarriquenha, cubana, equatoriana, espanhola, mexicana, nicaraguense, peruana, uruguaia e venezuelana) do que de língua inglesa (canadense, estadunidense, indiana moderna, inglesa, neozelandesa), é preciso lembrar que essa antologia foi estruturada em período anterior à internet e ao "boom" comercial-editorial da globalização. Logo, a presença de qualquer conto na antologia dependia de os organizadores terem acesso a livros originais, sendo que, desde o final da Primeira Guerra Mundial, a importância político-econômica e também cultural dos Estados Unidos só fez crescer, estabelecendo o inglês como língua de cultura que suplantou, no Brasil, a língua francesa. Na esteira desse movimento, cresceu a 
presença de livros de língua inglesa importados sendo, por outro lado, mais raro haver disponibilidade de livros de literaturas mais periféricas, ainda que produzida em países mais próximos e até mesmos vizinhos de língua espanhola da América Latina. Os 37 contos traduzidos diretamente do inglês correspondem, em termos percentuais, a 15,22\% do total de contos da antologia, enquanto os 26 traduzidos do espanhol correspondem a $10,70 \%$ e aqueles 34 traduzidos diretamente do francês representam 14\%. Essa diferença pequena entre o inglês e o francês como línguas de partida das traduções apontam para a consolidação da língua inglesa como língua de cultura, como mencionado, suplantando o francês que, até o início do século XX, tinha esse status no Brasil. ${ }^{7}$

Outro aspecto importante é a questão das traduções diretas e das indiretas. Embora Rónai fosse poliglota e Aurélio traduzisse do francês e do espanhol, dada a envergadura da antologia que almejava apresentar a maior variedade possível de contos relativamente a países, culturas, idiomas e épocas diferentes, seria inevitável que os organizadores se deparassem com contos escritos em idiomas que não dominassem. Segundo Rónai, ficou estabelecido entre eles que Aurélio se encarregaria traduzir para o português contos escritos originalmente em francês e espanhol, enquanto ele, Rónai, traduziria aqueles escritos em alemão, inglês, italiano, russo, grego, latim e húngaro, sua língua natal (RÓNAI, 1981, p. 170). Para os demais idiomas, o primeiro impulso dos organizadores foi procurar colaboradores "que tivessem um desses idiomas como língua materna e, ao mesmo tempo, conhecimento razoável do português" (RÓNAI, 1982, p. 170). A tais colaboradores, eles pediram "uma tradução literal, crua", um tipo de rascunho que depois seria burilado por Rónai e Aurélio. Porém, como relata Paulo Rónai,

[...] acabamos percebendo que a falta de inclinação ou de prática literária em parte de nossos colaboradores produzia muitas vezes um mot à mot cheio de armadilhas, às quais nem sempre conseguíamos escapar enquanto revíamos o trabalho. Pareceu mais oportuno recorrer a traduções indiretas de valor comprovado e, assim, pudemos ter acesso a literaturas exóticas como a chinesa, a persa, a hindu, a finlandesa, a catalã, a flamenga, a iídiche (RÓNAI, 1981, p. 170).

$\mathrm{Na}$ imagem abaixo, podemos ver o número contos escritos originalmente em português, o número daqueles traduzidos diretamente a partir do idioma em que o conto foi criado e, também, o número de contos traduzidos por intermédio de um outro idioma por Rónai e Aurélio, uma vez que as traduções indiretas partiram, todas, de idiomas que dominavam ${ }^{8}$. Há, ainda, o número de contos traduzidos por colaboradores partindo de idiomas que os organizadores não dominavam e, depois, revistos por eles: 


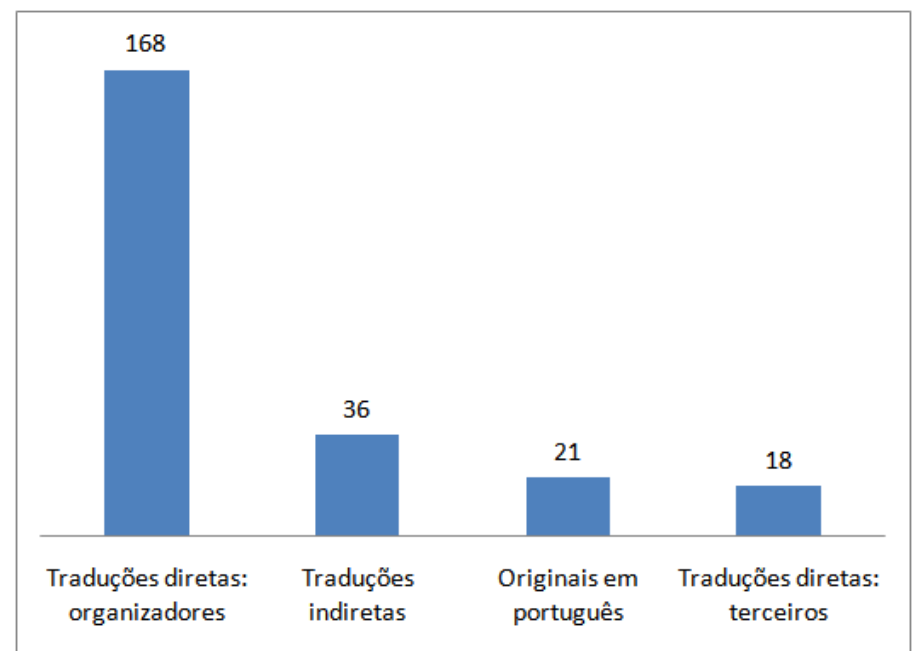

Figura 2: Número de contos não traduzidos, traduzidos diretamente ou indiretamente pelos organizadores, e traduzidos por terceiros.

A partir dessa distribuição, podemos calcular composição linguística de Mar de Histórias. Dos 243 contos presentes nos 10 volumes da obra, 222 foram traduzidos, correspondendo a $91 \%$ de traduções; já os originais em português são em número de 21 (13 brasileiros e 8 portugueses), correspondendo a 9\% de presença na antologia. Desse total de traduções, 186 contos foram traduzidos diretamente do original (168 pelos organizadores e 18 por colaboradores), perfazendo $76 \%$ e, por fim, as 36 traduções indiretas correspondem a 15\% de participação na antologia. O gráfico abaixo ilustra esses percentuais:

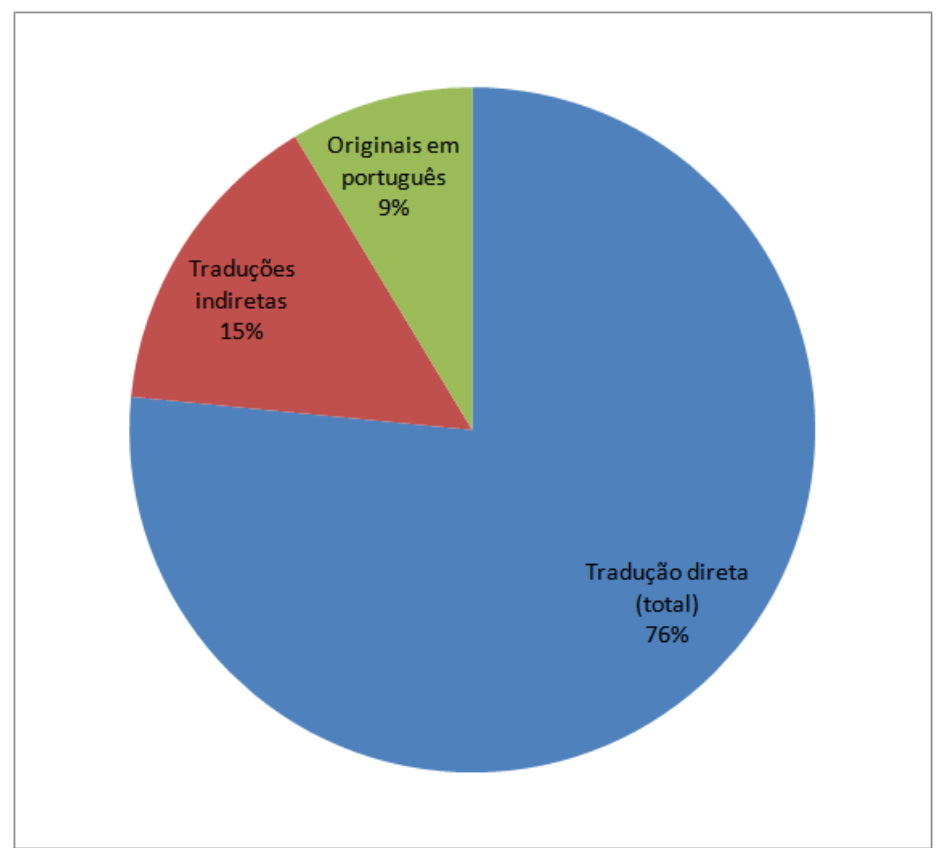

Figura 3: Distribuição percentual de originais em português, traduções diretas e traduções indiretas.

\section{Mar de Histórias e a Bildung de novos escritores}

A importância de uma obra como Mar de Histórias pode ser destacada, ainda, pela contribuição capaz de proporcionar à formação de novos escritores. Das variadas dimensões do conceito, Berman aponta também a característica de ser "um auto-processo em que um 'mesmo' se desdobra até adquirir sua plena forma" (2002, p. 81). Esse 
desdobrar-se exige um percurso, um processo calcado na experiência, o movimento de levar o "mesmo" por uma transformação até consagrar-se "outro", em outras palavras, a Bildung

é também, enquanto viagem, [uma] experiência da alteridade do mundo: para ter acesso ao que, sob o véu de um tornar-se-outro, é na verdade um tornar-se-si, o mesmo deve fazer a experiência do que não é ele (BERMAN, 2002 p. 81-82).

A formação de novos escritores passa pela experiência do escrever e, também, de forma inextricável, pela experiência da leitura. A vantagem de se ler obras estrangeiras traduzidas para a Bildung de novos escritores foi muito bem colocada por Osman Lins, conforme ponderação sua reproduzida por José Paulo Paes em "A tradução literária no Brasil", texto que podemos encontrar no livro Tradução, a ponte necessária (1990), pois, ao mesmo tempo que reflete a concepção de evolução de sistemas literários jovens e periféricos pela interrelação com literaturas centrais dentro do polissistema literário, conforme a teoria dos polissistemas de Itamar Even-Zohar (1978), indica a relevância que, ainda hoje, Mar de Histórias pode ter para escritores e aspirantes a escritor:

\begin{abstract}
Necessita o escritor brasileiro, mais que os de expressão francesa ou saxônica, do convívio com outras literaturas. Tal convívio pode ocorrer mediante o conhecimento de outras línguas. Acho, entretanto, que produz melhores resultados quando o escritor dispõe de um número apreciável de obras bem traduzidas. Não apenas devido ao fato de que o escritor raramente domina vários idiomas, mas também porque o contato com o texto traduzido [...] permite uma fruição mais ágil, tendo ainda a vantagem de manter o fruidor de uma obra alienígena em contato com a sua própria língua (LINS apud. PAES, 1990, p. 1011).
\end{abstract}

Como fica patente ao percebemos a riqueza e amplidão de Mar de Histórias em termos de variedades de origens geográficas, linguísticas e temporais dos contos presentes na obra, esta proporciona a qualquer leitor, em especial o que é ou será também escritor, como destacado acima por Lins, ter contato com um número vastíssimo de temas, recursos e estilos literários. Esse potencial de influência positiva na formação, na Bildung de um escritor pode ser atestado, por exemplo, por um depoimento de Moacyr Scliar (19372011), um nome importante da literatura brasileira contemporânea, escritor de origem judaica, como o era Paulo Rónai. Segundo nos relata Scliar:

Eu cacei em sebos, um por um, os volumes de Mar de Histórias. Era ainda a época em que se ficava cortando as páginas com uma faca. Eu comecei a carreira escrevendo contos e, como todo jovem contista, estava em busca de mestres (SCLIAR, 1999, A3).

Esse o depoimento de Scliar, que faz parte da matéria intitulada "Falam os lobos do mar" publicada pela da Folha de S.Paulo em 1999 na época do lançamento da $4^{\text {a }}$ edição de Mar de Histórias, tem por companhia depoimentos de outros ilustres admiradores, quiçá tributários, da antologia, como Davi Arrigucci Jr., Modesto Carone e Rachel de Queiroz. Carone, que além de famoso por ter se especializado na tradução de obras de Franz Kafka, é também escritor e professor de literatura. Ele relata que leu Mar de Histórias e o considera "a mais vasta e bem recheada antologia de contos mundiais que eu conheço em língua portuguesa", e também afirma: "No geral, as escolhas são certeiras, muitas vezes originais, e a tradução dos textos é cuidada. Paulo Rónai e Aurélio Buarque de Holanda são eruditos que deram certo" (CARONE, 1993, A3). Quanto ao depoimento de Arrigucci, 
escritor, ensaísta e professor de literatura da USP, vale a pena finalizarmos este artigo citando o seguinte trecho:

Quando comecei a tomar gosto pela literatura, senti verdadeiro fascínio pelos contos inesquecíveis do Mar de Histórias [que] talvez seja a melhor das antologias de contos já publicadas entre nós: pela amplitude da visão, que introduziu autores até então desconhecidos em nosso meio; pelo acerto da maioria das escolhas; pelo alto nível das traduções, feitas quase sempre diretamente das línguas originais; pelas excelentes notas crítico-informativas sobre os contistas e suas obras. A sugestão épica da viagem se abre com o título e a alusão ao mar, como um chamado à imaginação do leitor: a multiplicidade e o movimento dos contos, que vêm de toda parte, sustentam a sedução e tudo faz pensar que a arte de narrar é de fato um dos maiores dons do homem e um dos melhores meios que encontrou para conhecer a si mesmo e a sua própria história (ARRIGUCCI, 1999, A3).

\title{
Mar de Histórias and the concept of Bildung
}

\begin{abstract}
Mar de Histórias: Antologia do Conto Mundial is a ten-volume anthology with short-stories from a great variety of national and linguistic origins, comprehending a time period that spans from the Antiquity to the period between World Wars. This impressive translational-literary accomplishment was carried out in Brazil by Paulo Rónai and Aurélio Buarque de Holanda Ferreira. This paper aims at tracing an interrelation between this work and the concept of Bildung, as presented by Antoine Berman (2002), focusing on three different aspects: Bildung as an orienting principle for the project's organization; as a basis for presenting an overview of the anthology; and as a tool for the Bildung of new writers.
\end{abstract}

Key-words: world literature; translation; anthology; Bildung, Paulo Rónai.

\footnotetext{
* Adauto Villela é doutor em Letras: Estudos Literários pelo PPG-Letras da Universidade Federal de Juiz de Fora (UFJF) e professor do Bacharelado em Letras: Tradução da Faculdade de Letras da UFJF.

${ }^{1} \mathrm{O}$ presente artigo baseia-se em parte dos capítulos 2 e 3 de minha tese de doutorado intitulada "Paulo Rónai e o Mar de Histórias: a prática crítico-literária de um intelectual húngaro no exílio" (VILLELA, 2012).

${ }^{2}$ Foi graças a um projeto tradutório, um livro de poesias brasileiras traduzidas para o húngaro, que Rónai travou contato com diplomatas brasileiros, entre os quais João Guimarães Rosa e Rui Ribeiro Couto. O livro se chamava Brazília üzen: mai brazil költök (Mensagem do Brasil: os poetas brasileiros da atualidade) e foi publicado em setembro de 1939 (cf. VILLELA, 2012, p. 37-41).

${ }^{3}$ Tanto Escola de tradutores ( $7^{\mathrm{a}}$ edição) quanto A tradução vivida ( $5^{\mathrm{a}}$ edição) foram reeditados em 2012 pela José Olympio.

${ }^{4} \mathrm{Na}$ tradução brasileira de A comédia humana de Honoré de Balzac - projeto em participou como coordenador da equipe de tradutores, revisor das traduções e organizador geral -, Rónai redigiu introduções e notas para cada uma das 89 obras presentes nos 17 volumes em que foram publicadas. Além disso, redigiu nada menos que 7.493 notas de rodapé (cf. ESQUEDA, 2004).

${ }^{5}$ No estudo introdutório para o livro Poesia, de Ezra Pound, Augusto de Campos aponta que uma função fundamental da crítica é a seleção: "a ordenação geral e a mondadura do que está sendo realizado; a eliminação de repetições; o estabelecimento do paideuma: a ordenação do conhecimento de modo que o próximo homem (ou geração) possa o mais rapidamente achar a parte viva dele e gastar um mínimo de tempo com itens obsoletos" (CAMPOS, 1983, p. 23).

${ }^{6}$ Pela primeira vez no histórico da obra, os volumes dessa edição foram disponibilizados também em versão eletrônica, além da tradicional versão impressa.

${ }^{7}$ Podemos lembrar, ainda, que as traduções de contos de língua inglesa tiveram presença destacada também na supracitada coluna "Conto da semana" do Diário de notícias (1954 a 1960), conforme se lê em Spiry (2009, p. 1902-202).

${ }^{8}$ Mais especificamente, as 36 traduções indiretas tiveram, como língua intermediária, 14 traduções partindo do alemão, 13 do francês, 7 do inglês e 2 do espanhol. Como se pode notar, o idioma que mais intermediou
} 
as traduções para o português não foi o francês, ao contrário do que se poderia esperar, mas o alemão. Não por acaso, a importância da tradução para cultura alemã a partir do final do século XVIII é um aspecto também destacado por Berman (2002, p. 86-87).

\section{REFERÊNCIAS}

ARRIGUCCI, David. Falam os lobos-do-mar. Folha de S.Paulo, 24 abr. 1999. Ilustrada, p. 3.

BERMAN, Antoine. A prova do estrangeiro: cultura e tradução na Alemanha romântica - Herder, Goethe, Schlegel, Novalis Humboldt, Schleiermacher, Hölderlin. Trad. Maria Emília Pereira Chanut. Bauru: EDUSC, 2002. 350 p.

CAMPOS, Augusto. Ezra Pound: "nec spe ne nec metu". In: POUND, Ezra. Poesia. Traduções de Augusto e Haroldo de Campos, Décio Pignatari, José Lino Grünewald e Mário Faustino. Brasília: Hucitec, Editora da Universidade de Brasília, 1983. p. 12-20.

CARONE, Modesto. Falam os lobos-do-mar. Folha de S.Paulo, São Paulo, 24 abr. 1999. Ilustrada, p. 3.

EVEN-ZOHAR, Itamar. The position of translated literature within the literary polysystem. In: Holmes, J. S. et al. (ed.). Literature and translation: new perspectives in literary studies. Leuven: Acco, 1978. p. 117-127.

ESQUEDA, Marileide Dias. O tradutor Paulo Rónai: o desejo da tradução e do traduzir. Tese (Doutorado em Linguística Aplicada à Teoria da Tradução). Campinas: Universidade Estadual de Campinas, 2004. $213 \mathrm{f}$.

PAES, José Paulo. Sobre a crítica de tradução. In: ---. Tradução, a ponte necessária: aspectos e problemas da arte de traduzir. São Paulo: Editora Ática, 1990. p. 108-116.

RÓNAI, Paulo. A tradução vivida, 3 ed. Rio de Janeiro: Nova Fronteira, 1981. 210 p.

Mar de Histórias e a tradução da grande obra literária: depoimento. Revista Tradução \& Comunicação, São Paulo, v. 1, n. 2, p. 1-19, 1982.

RÓNAI, Paulo; FERREIRA, Aurélio Buarque de Holanda. Mar de histórias: antologia do conto mundial. 4 ed. Rio de Janeiro: Nova Fronteira, 1999a, v. 1. Das Origens ao fim da Idade Média. $295 \mathrm{p}$.

SCLIAR, Moacyr. Falam os lobos-do-mar. Folha de S.Paulo, São Paulo, 24 abr.1999. Ilustrada, p. 3.

SPIRY, Zsuzsanna Filomena. Paulo Rónai: um brasileiro made in Hungary. Dissertação (Mestrado em Estudos Linguísticos e Literários em Inglês). São Paulo: Universidade de São Paulo, 2009. 202 f.

SUAREZ, Rosana. Nota sobre o conceito de Bildung (formação cultural). Kriterion [online]. 2005, vol.46, n.112, pp.191-198.

VILLELA, Adauto. Paulo Rónai e o Mar de Histórias: a prática crítico-literária de um intelectual húngaro no exílio. Tese (Doutorado em Letras: Estudos Literários). Juiz de Fora: Universidade Federal de Juiz de Fora, 2012. 221 p. 